F. C. BUBBERMAN

\title{
ROTSTEKENINGEN
}

\section{IN DE SIPALIWINISAVANNE}

Een bijdrage tot de archeologie van Zuid-Suriname

Al vroeg moet de mens de mogelijkheden hebben ontdekt om zichtbaar uiting te geven aan zijn gedachtenleven, waarbij met gebruikmaking van natuurlijke materialen met grote vaardigheid bepaalde voorstellingen werden vastgelegd. Een aparte plaats wordt hierbij ingenomen door figuren, welke in rotsoppervlakken zijn gegraveerd: de rotstekeningen of, scherper bepaald, petroglyphen, daar onder rotstekeningen ook geschilderde figuren kunnen worden verstaan. In sommige gevallen schijnen de beweegredenen tot het scheppen van deze vroege kunst wel vast te staan zoals een of andere vorm van geschiedschrijving of magische verering - in de meeste gevallen ligt een bevredigende verklaring der figuren echter niet voor de hand.

Op vele plaatsen in het stroomgebied van de Amazone en Orinoco en in het binnenland van Suriname werden zulke precolumbiaanse petroglyphen ontdekt. De oudste melding is die van Nikolas Horstmann, die op i6 april I749 rotstekeningen aantrof aan een der oevers van de Rupununi in Guyana.

Ook in Suriname, waar zij evenals in Guyana bekend staan als Timehri - volgens AHLBRINcK (I93I) afgeleid van de Karaïbsindiaanse uitdrukking ti-me-re (van tekeningen voorzien) - komen sporen voor van deze primitieve kunst. Reeds KAPPLER (I887) en SchомвURGк (I84I) maken melding van rotsinscripties in respectievelijk de Marowijne en de Corantijn. Enkele van de laatste zijn afgebeeld in Downer's Map of Berbice van I844. De ontdekkingsreizen, nog vóór de eeuwwisseling, van BRETT, BARRINGTON BROWN en IM THURN brachten meer petroglyphen aan het licht op verschillende plaatsen in het Corantijnstroomgebied, evenals de verkenningstochten van KÄYSER, FARABeE, Roth, Gonggryp, Stahel en Ahlbrinck in het begin van de $20 e$ eeuw, en van GeijSkEs en DubelaAR daarna. 
In Suriname zijn tot nu toe petroglyphen witsluitend aangetroffen in de stroomgebieden der beide grensrivieren, de Marowijne en de Corantijn. Ondanks de vele, vooral in de laatste tijd uitvoerige, verkenningen werden van de stroomgebieden der tussenliggende rivieren geen vondsten gemeld. De Surinaamse rotsinscripties worden in het nog niet gepubliceerde onderzoek van $\mathrm{C}$. N. DUBELAAR onderscheiden in verschillende typen, welke ten dele overeenkomen met de indeling van Im THURN (I883) in deep engravings en shallow engravings. ${ }^{1}$ Van de eerstgenoemde groep, vermoedelijk de oudste, komen voorbeelden voor in beide genoemde grensrivieren. De veronderstelling van GONGGRYP (I920), dat de makers van deze inscripties zich in Suriname hebben verplaatst van Zuid naar Noord, van de oorsprong der beide grensrivieren in de richting van de kust en niet omgekeerd, lijkt daarom aanvaardbaar, omdat in het omgekeerde geval petroglyphen in de andere riviersystemen ook te verwachten zouden zijn geweest.

\section{EEN INSCRIPTIE BIJ DE ZUIDGRENS}

Het bovenstaande gaf aanleiding tot het vermoeden, dat in het zuidelijke grensgebied van Suriname met Brazilië, waar de bronrivieren van Marowijne en Corantijn dicht bijeen hun oorsprong hebben, ook petroglyphen voor zouden komen. Vooral de Sipaliwinisavanne, ${ }^{2}$ waar het stroomgebied van de Surinaaamse Corantijn bijna ongemerkt overgaat in dat van de Braziliaanse Paru de Oeste, die tot het stroomgebied van de Amazone behoort, leek op dit punt veelbelovend. Immers, een trekroute vanuit het Amazonegebied langs de Paroe over de waterscheiding naar de Surinaamse rivieren ligt geografisch niet alleen voor de hand maar werd nog tot in historische tijd door de feiten bewezen. Bovendien werden door Dost in 1962 in de Sipaliwinisavanne oud-indiaanse artefacten aangetroffen. Daarom werd door schrijver dezes, in de gelegenheid om een deel der eerste Wotro-expeditie in de noordelijke helft van de Sipaliwinisavanne mede te maken, in november I968, naar mogelijke rotstekeningen gezocht, echter zonder succes. Wel werden bij deze gelegenheid gegevens verkregen, die het bestaan van rotsinscripties in de Sipaliwinisavanne nog waarschijnlijker maakten. Bij een ontmoeting namelijk in het dorp Missao Tirió, aan de Braziliaanse zijde van de grens, met de stichter van de missiepost, ex-Pater G. P. FrICKEL, op dat moment verbonden aan het Museu Paraense Emilio 
Goeldi te Belém do Para, werd door hem mededeling gedaan van de vondst van petroglyphen bij grotingangen in de in Brazilië gelegen voetheuvels van het Grensgebergte. Deze voetheuvels, aldaar aangeduid met de naam Contraforte, vormen de noordelijke begrenzing van het dal van de Paru de Oeste. Sommige inscripties vertoonden volgens zegsman sterke gelijkenis met aan hem bekende afbeeldingen van inscripties bij de Wonotobovallen in de Corantijn. Een beschrijving werd echter niet verkregen.

Zodra het seizoen weer gunstig was, werd dan ook in november I969 door schrijver dezes, thans tezamen met de geoloog Ir. J. J. JANSSEN, een tweemans-expeditie ondernomen nu naar het zuidelijk deel van de Sipaliwinisavanne. Daarbij werd vooral aandacht besteed aan een rij van afzonderlijke bergtoppen in het grensgebied op ongeveer zeven kilometer ten zuidoosten van het Viergebroedersgebergte. Bij de beklimming van een lage heuvel, die deze rij naar het noordwesten afsluit, trok een grote, rechtopstaande steen, die eenzaam midden op de vlakke top stond, van verre reeds de aandacht. En wie schetst onze vreugde bij het aanschouwen, even later, van echte petroglyphen; de eerste in Suriname, die niet in de directe omgeving van water werden aangetroffen. Blijkbaar zijn zij bij de verkenningen der grote grensexpeditie in I936 onder vAN LYNDEN, die dit punt, op ca. vier kilometer ten westen van de grens, zeker gepasseerd is, niet opgemerkt want zij worden in zijn verslag niet vermeld.

\section{PlaAts}

Zoals gezegd zijn deze petroglyphen de eerste in Suriname, die niet bij of aan het water zijn aangetroffen. Dat dit ook elders een uitzondering is bewijzen o.a. de uitspraken van IM THURN (I883) en TEN KATE (I9I6, p. 543), die stellen, dat het voorkomen van inscripties bij het water en vooral bij stroomversnellingen een algemeen kenmerk is. De door ons gevonden petroglyphen bevinden zich op de waterscheiding tussen de zuidelijke zijtak van de Surinaamse Viergebroeders Kreek, een zijtak van de Sipaliwini, die weer een der bronrivieren is van de Corantijn, en de Braziliaanse Rio de 26 Novembre, een kleine zijtak van de Paru de Oeste, die weer een zijrivier is van de Cumina, die via de Trombetas in de Amazone uitstroomt. Op de top van een ongeveer $70 \mathrm{~m}$ hoge, vlakke, afgeronde, met gras en schaarse boompjes begroeide heuvel staat een langwerpige steen, die opvalt door plaats en vorm. Deze heuvel is de noordelijkste van een Z.O.-N.W. 
gerichte serie bergen en heuvels, waarvan de meeste andere veel hoger zijn, en ligt op een punt $\mathrm{I}^{\circ} 7^{\prime} 36^{\prime \prime}$ N.B. en $55^{\circ} 6^{\prime} 45^{\prime \prime}$ W.L., dus op Surinaams gebied (Afb. 2).

\section{BESCHRIJVING}

De eenzame steen, ca. $2.20 \mathrm{~m}$ hoog, $1.20 \mathrm{~m}$ breed en $0.80 \mathrm{~m}$ dik, is aan één zijde en aan de top afgerond, maar aan de andere naar het oosten gekeerde zijde afgeplat en helt in die richting enigszins over. De steen is het overeind gebleven gedeelte van een groter granietblok, dat zoals zovele andere in dit gebied uiteen is gevallen. De afgeplatte zijde is kennelijk ontstaan door splijting als gevolg van fysische verwering langs een breuk. Afgezien van een scheur langs de top van de steen is de rest geheel vrij van scheuren. Op de onderste helft van de platte, naar het oosten gekeerde zijde van de steen bevindt zich de inscriptie op een toch betrekkelijk ruw oppervlak. Deze inscriptie bestaat uit zeven afzonderlijke figuren, waarvan vijf duidelijk als menselijke gestalten te herkennen zijn. Hoewel zeer wel werd begrepen dat het verduidelijken der figuren met krijt gemakkelijk aanleiding zou kunnen geven tot eigen kunst werd ter wille van de fotografie daartoe overgegaan. Daarbij bleken de lijnen met de vinger toch duidelijk voelbaar te zijn en gesteld kan worden, dat zeker geen details werden toegevoegd of overgeslagen. Ten aanzien van de inscriptie zelf vallen op: de tweehoofdigheid der bovenste figuren, het verschil in afmetingen tussen de figuren onderling en de toevoeging van twee extra figuren aan de dubbele menselijke gedaante linksboven (Afb. 4). Deze figuur is de grootste en meet $53 \mathrm{~cm}$ in de lengte van hoofdkruin tot hoofdkruin, en $4 \mathrm{I} \mathrm{cm}$ in de breedte van elleboog tot elleboog. De beide daarnaast staande figuren zijn nagenoeg gelijk van afmeting; van links naar rechts: lengte 46 en $48 \mathrm{~cm}$ en breedte 29 en $28 \mathrm{~cm}$. De onderste twee menselijke figuren zijn weer kleiner, maar onderling vrijwel gelijk en meten in dezelfde volgorde: 24 en $25 \mathrm{~cm}$ in de lengte en $\mathrm{r} 8 \mathrm{~cm}$ in de breedte. De figuur linksboven domineert dus de beide andere groepen. De diepte der lijnen is niet overal gelijk, maar is met een maximum van $\frac{1}{2} \mathrm{~cm}$ op sommige plaatsen zelfs zeer duidelijk zichtbaar. In aanmerking nemend dat door de chemische verwering van het graniet door de daarop groeiende wieren en korstmossen het verschil tussen het ruwe oppervlak van het gesteente en de lijnen vervaagt, kan deze inscriptie, ook al wat betreft de voorstellingen zelf, zeker worden gerangschikt onder de deep 
engravings waarvan IM THURN ${ }^{1}$ veronderstelt dat zij zijn verkregen door ze in het gesteente te beitelen. Wellicht vormt het onvoltooide onderstel van de figuur rechtsonder van de Sipaliwini-inscriptie een aanwijzing voor het feit dat hier inderdaad sprake is van beitelen, omdat de vrije ruimte, die voor het beitelen nodig is, op die plaats wordt beperkt door een daarvoor liggend granietblok. Het is niet waarschijnlijk, dat de figuur om andere redenen onvoltooid gelaten zou zijn omdat het geheel van de inscriptie juist een zeer complete indruk maakt. Ook de ongelijkmatige diepte der lijnen pleit voor genoemde veronderstelling.

Wat betreft de betekenis der Sipaliwini-petroglyphen zou de tweehoofdigheid der figuren toch wel op een zekere symboliek kunnen wijzen. In het verslag van zijn reis naar Suriname verklaart ook FERIZ (I957) de betekenis van enkele figuren op de zgn. Oayanaborden vanuit de o.m. bij sommige indianenstammen algemeen levende overtuiging van de bipolariteit van de natuur, waaruit de neiging voortkomt tot het afbeelden van dubbele figuren. ${ }^{3}$ Het lijkt aannemelijk te veronderstellen, dat de steen met inscripties een trekroute markeert; hij bevindt zich immers op de waterscheiding tussen twee bevaarbare rivieren op een strategisch punt in een rij heuvels, die tezamen een soort landbrug vormen, aan beide zijden door moerassen omgeven (Afb. 8).

\section{Artefacten}

Op de heuvel rondom de steen werden verspreide artefacten gevonden. Naar aanleiding daarvan dient te worden opgemerkt, dat in de Sipaliwinisavanne de bestudering van oppervlaktevondsten veelal het enig mogelijke is. Door de eeuwenlange afspoeling van het schaars begroeide terrein, dat bovendien herhaaldelijk aan vegetatiebranden onderhevig is, zijn de artefacten als het ware uitgeprepareerd, waarbij uiteraard de stratificatie verloren is gegaan. Inventarisatie van de in de omgeving der inscriptie gevonden artefacten, waarvan dus met zekerheid mag worden aangenomen, dat zij door de langdurige afspoeling van het schaars begroeide terrein vrijwel alle aan de oppervlakte zijn gekomen, leverde de volgende feiten op.

$I$. Op de inscriptieheuvel zelf werden verspreid enkele kleine obsidiaan-splinters aangetroffen, waarvan geen enkele in de directe omgeving van de steen met inscripties. Dit verschijnsel - verspreide vuursteensplinters soms tezamen met een gave of een in twee stukken gebroken pijlspits op een heuveltop - is typisch 
voor een groot deel der Sipaliwinisavanne en duidt op een door het gehele gebied verspreide palaeo-indiaanse cultuur van jagers, waarvan elders in de savanne ook enkele duidelijk geconcentreerde werkplaatsen zijn aangetroffen. Deze locatie is een gevolg van het feit, dat de vroegere jagers het materiaal, bij voorkeur het glasachtige homogene obsidiaan, dat slechts in smalle aders voorkomt, blijkbaar naar behoefte ter plaatse bewerkten. Uiteraard treden deze aders slechts boven òp de door verwering en erosie aangetaste heuvels aan de dag. Ook door ons werden zo enkele ruwe stukken vulkanisch glas op heuveltoppen tussen de verweerde steenblokken gevonden.

2. Ook werden op de heuvel enkele verspreide potscherven gevonden. Deze behoren, gezien de ornamentering, tot de uit de historie bekende Taruma-cultuur. Dergelijke potscherven werden op andere plaatsen in de Sipaliwinisavanne in grote concentraties gevonden, vooral op de toppen der hoogste bergen: Morro Grande, Viergebroeders en de hoge bergen uit de landbrug ten zuidoosten van de inscriptieheuvel. Zij getuigen van een op hoog peil staande pottenbakkerskunst. Uit historische bronnen is bekend, dat de Taruma's na I670 uit het zuiden, vanuit hun oorspronkelijk woongebied aan de monding van de Rio Negro, voor de druk der Portugese kolonisatie in het Amazone gebied, noordwaarts zijn uitgeweken en zich hebben gevestigd aan de bovenloop van de Essequibo in het zuiden van Guyana (GupPy, I958; Evans \& MEGGERS, I960). De vondsten van typisch Taruma-aardewerk in Suriname, in de Sipaliwinisavanne en langs de Coeroeni (GEYSKES, I959), bewijzen dat hun verspreidingsgebied veel groter was dan alleen het zuiden van Guyana. ${ }^{4}$ Ongetwijfeld worden met de gevreesde Saloema's, van wie DE GoEJE (I908) en KÄYSER (I9I2) melding maken bij hun bezoeken aan het zuiden van Suriname in de jaren 1907 en I9II, ook afstammelingen van deze Taruma's bedoeld (RoTH, I925).

3. Op de oostelijke voet van de inscriptieheuvel, niet ver van een ook in dat droge seizoen nog voldoende water bevattende kreek, en op enige plateau's ten oosten van die kreek werden grotere concentraties van artefacten, als enige in de meer directe nabijheid van de inscriptie aangetroffen. Aan de oppervlakte werden grove, onversierde, verweerde potscherven gevonden, alsmede de over enkele vierkante meters verspreide onderdelen van een geheel gedesintegreerde, primitieve, geslepen stenen bijl of vuistwig (Afb. I2). Deze grove potscherven, bestaande uit uitsluitend met zand en steentjes vermagerde klei, waaronder ook fragmen- 
ten van zgn. bakplaten (zie MEgGers \& Evans, I963, p. I35) werden op verschillende andere plaatsen in de Sipaliwinisavanne aangetroffen, vooral langs de grotere kreken, in één geval in de directe omgeving van een uitgebreid slijpgroevencomplex in een der noordelijke zijtakken van de Viergebroederskreek. Dit aardewerk wijkt in aard en samenstelling geheel af van het Tarumaaardewerk en moet dus, daar het Taruma-aardewerk tot in historische tijden dit gebied heeft beheerst, ouder zijn.

\section{OUDERDOM}

Ten aanzien van de leeftijdsbepaling van petroglyphen moet worden gesteld, dat deze, overeenkomstig de gangbare principes, slechts mogelijk is wanneer een duidelijke relatie bestaat met voorwerpen, die door hun koolstofgehalte geschikt zijn voor de radio-carbonmeting. Dat betekent dat in de meeste gevallen de ouderdom der petroglyphen onbekend is. Bij de Sipaliwiniinscriptie echter lijkt het bepalen van een relatie tot de aard der omliggende vondsten mogelijk te zijn.

Immers, het lijkt niet waarschijnlijk, dat de dragers van de palaeo-indiaanse cultuur, die in deze streken vanaf omstreeks 6000 jaar voor onze jaartelling (ZERRIES, I968, p. 329) kan hebben bestaan, verantwoordelijk zijn voor de inscriptie, omdat het overgebleven afval daar niet op wijst. Wat dit betreft is de situatie op de heuvel geheel gelijk aan die op vele andere heuvels in de savanne, waar geen inscripties voorkomen. Het verblijf van deze mensen op de inscriptieheuvel en op andere heuvels in wijde omgeving is slechts van zo lange duur geweest als nodig was om het gevonden materiaal te testen of te bewerken. Het lijkt ook niet waarschijnlijk dat de leden der Taruma-stam, die zoals vermeld omstreeks I7oo n. C. in dit gebied moeten zijn aangekomen, de inscriptie hebben aangebracht. Was dat wel zo, dan zouden van hun aardewerk ook zeker veel meer overblijfselen op of om de heuvel te vinden zijn geweest. Trouwens, alle reizigers, die vanaf het midden der negentiende eeuw het grensgebied tussen het Amazonebekken en de Guyana's bezochten, trokken uit hun contacten met de aangetroffen bewoners, onder wie ook de toen nog levende Taruma's langs de bovenloop der Essequibo in Guyana, de conclusie, dat de petroglyphen blijkbaar door vertegenwoordigers van oudere, toen reeds verdwenen stammen moesten zijn gemaakt. 5 
De oudste thans bekende overblijfselen in dit gebied van menselijke activiteiten ná het palaeo-indiaanse tijdperk, in de vorm van aardewerk fragmenten, stammen pas uit een periode $n a$ omstreeks 500 jaar voor onze jaartelling (ZERRIES, I968, p. 346). In de jaren hierna is het Amazonegebied het toneel geweest van volksverhuizingen, waarbij verscheidene groepen immigranten elkaar vanuit het noordwesten en westen hebben opgevolgd of in ieder geval beïnvloed, ${ }^{6}$ gebruik makend van de riviersystemen (Afb. I3). Aangenomen wordt dat omstreeks het jaar rooo, wanneer de bakplaat in dit gebied verschijnt, bepaalde vormen van landbouw, o.a. de teelt van bittere kassave, bekend waren. Het tijdperk der Neo-indiaanse Tropenwoudculturen - gekenmerkt door kleine, vaak verplaatste nederzettingen, door een gemengde economie bestaande uit primitieve landbouw èn verzamelen van bosproducten, en door het gebruik van aardewerk en geslepen stenen werktuigen - is dan reeds in volle gang. ${ }^{7}$

Op grond van het bovenstaande mag worden vermoed, dat de gevonden inscriptie niet ouder is dan 2500 jaar, het tijdsverloop tussen 500 v.C. en heden. Hoewel bewijzen ontbreken, vindt dit vermoeden wel versterking door de aanwezigheid der genoemde concentraties primitieve potscherven op de oostelijke heuvelvoet. Het is niet zo moeilijk zich voor te stellen, dat daar, aan de boorden van een ook in het droge seizoen niet droogvallende kreek en onder bescherming van de steen op de heuvel, een primitieve neo-indiaanse nederzetting heeft bestaan. De veronderstelling van een relatie tussen de inscriptie en deze primitieve overblijfselen doortrekkend zou, waar inderdaad resten van bakplaten zijn aangetroffen, kunnen worden gesteld dat de ouderdom wellicht niet hoger is dan ca Iooo jaar (vgl. Meggers \& Evans, I963, p. I35).

In elk geval kan met aan zekerheid grenzende waarschijnlijkheid worden gezegd, dat de inscriptie in de Sipaliwinisavanne gemaakt moet zijn in de periode tussen het jaar $500 \mathrm{v} . \mathrm{Chr}$ en I700 n.Chr. en dat hij derhalve niet jonger is dan 250 jaar en niet ouder dan 2500 jaar. 


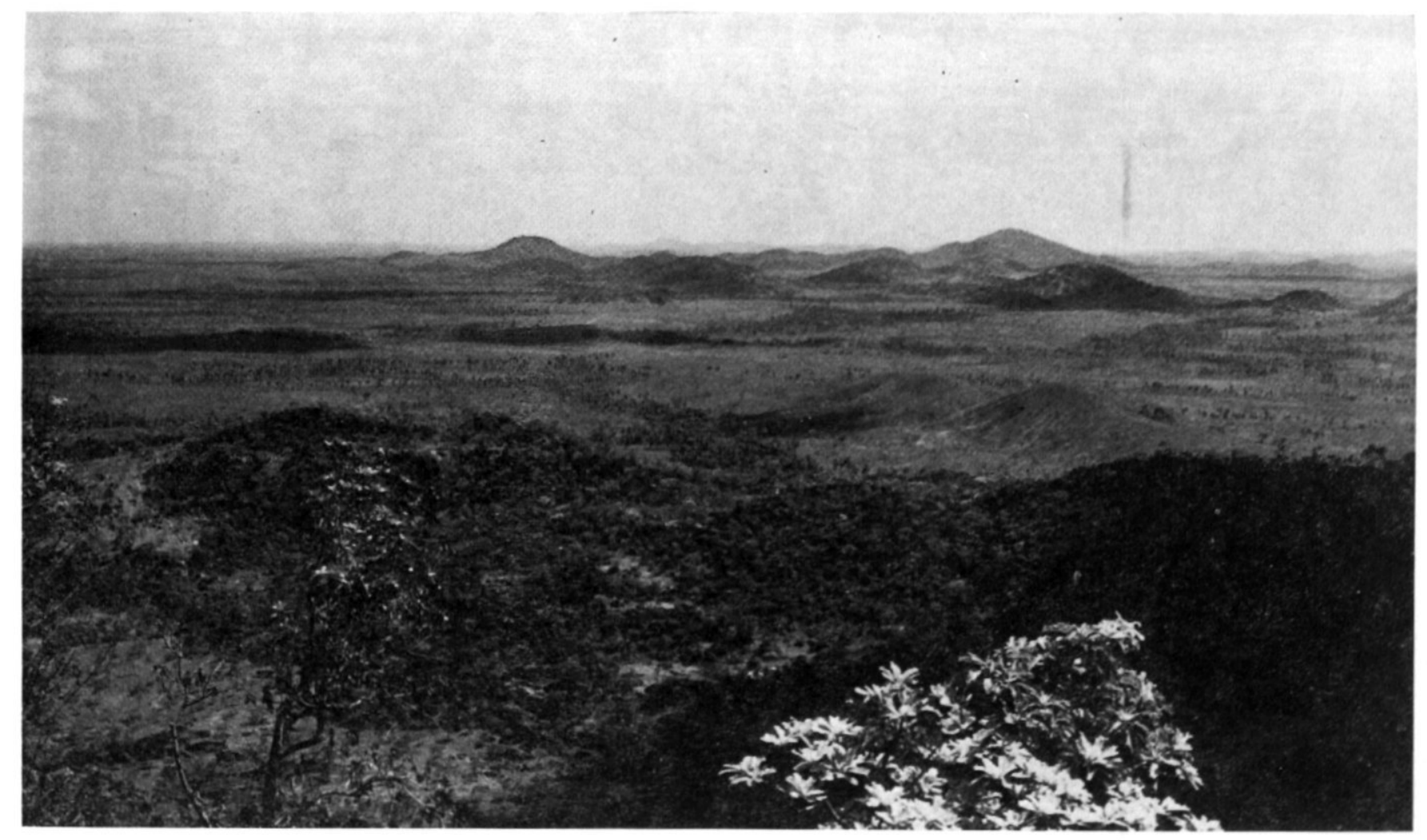

Fig. I. - Overzicht zuidwaarts over het zuidelijk deel van de Sipaliwinisavanne. - Het in Suriname liggende gedeelte van het grote savannegebied op de Zuidgrens beslaat een oppervlakte van ruim 63000 ha en wordt genoemd naar de voornaamste rivier in dat gebied. - Het heuvelige met gras en schaarse bomen begroeide terrein is thans geheel onbewoond, in tegenstelling tot voor dertig jaren, toen door ScHMidT (1942) nog verscheidene dorpen van de Trio-stam werden aangetroffen. Ook de inheemse naam voor deze streek, diapokoimape, staat niet (meer) op de kaart.

Fig. I. - View on the southern part of the Sipaliwini savanna, to the south. The savanna on Surinam territory covers an area of approx. 63,000 ha. This area is uninhabited. 


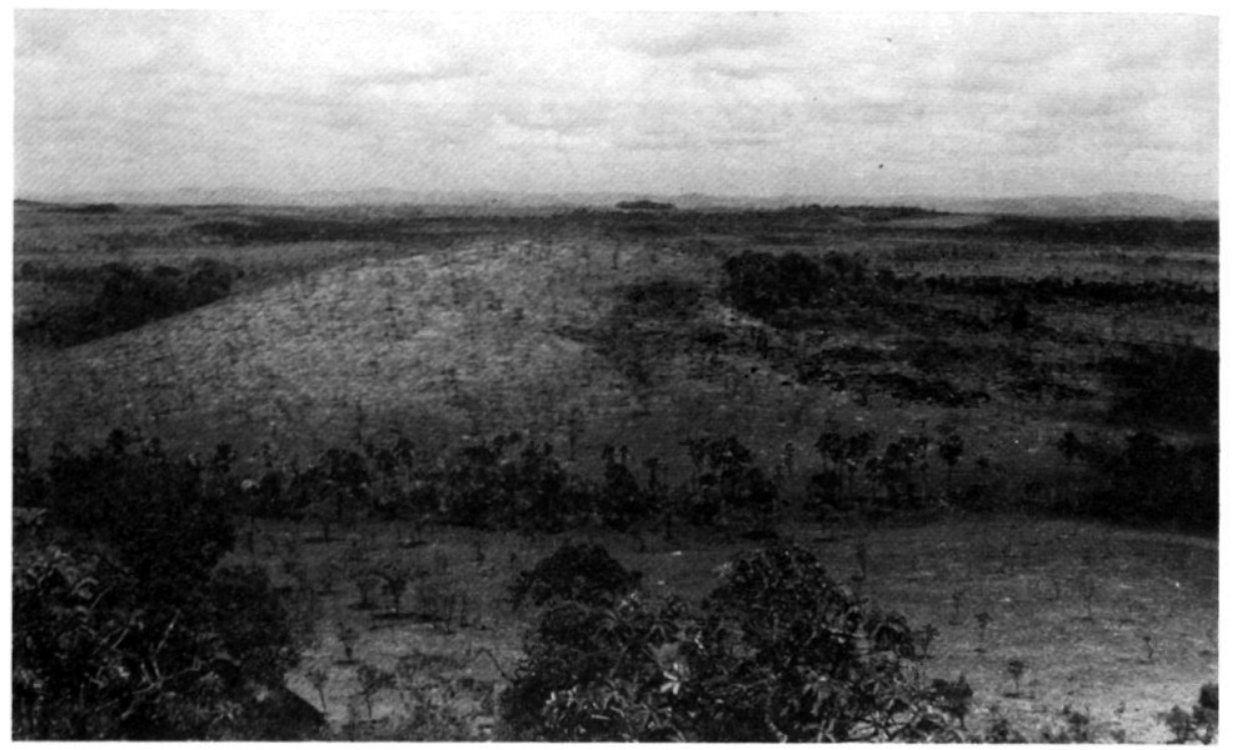

Fig. 2. - De heuvel met inscriptiesteen vanuit het Zuidwesten gezien. Op de achtergrond de in Brazilië gelegen noordelijke begrenzing van het Paroedal, het Grensgebergte (Contraforte).

Fig. 2. - The 'inscription hill' seen from the southwest. In the background the dividing range between Surinam and Brazil.

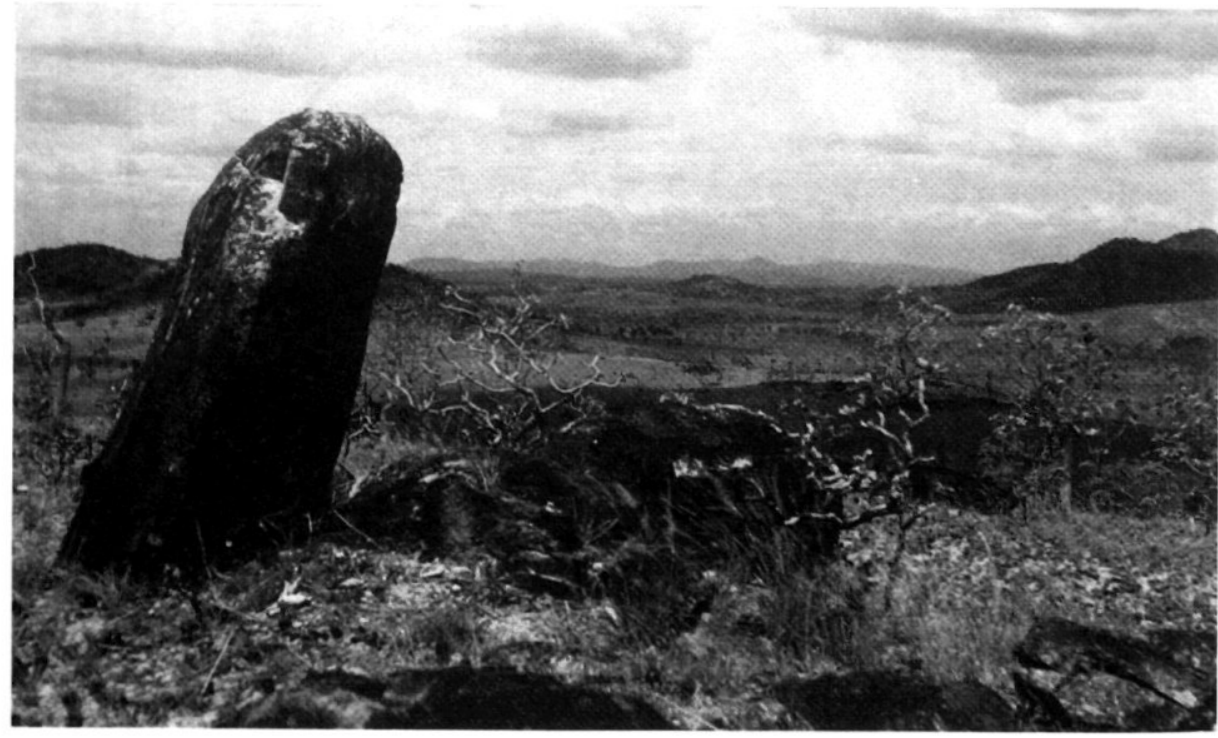

Fig. 3. - De steen met petroglyphen, met uitzicht naar het noordwesten. Rechts enkele toppen van het Viergebroedersgebergte.

Fig. 3. - The slab with petroglyphs on top of the hill. 


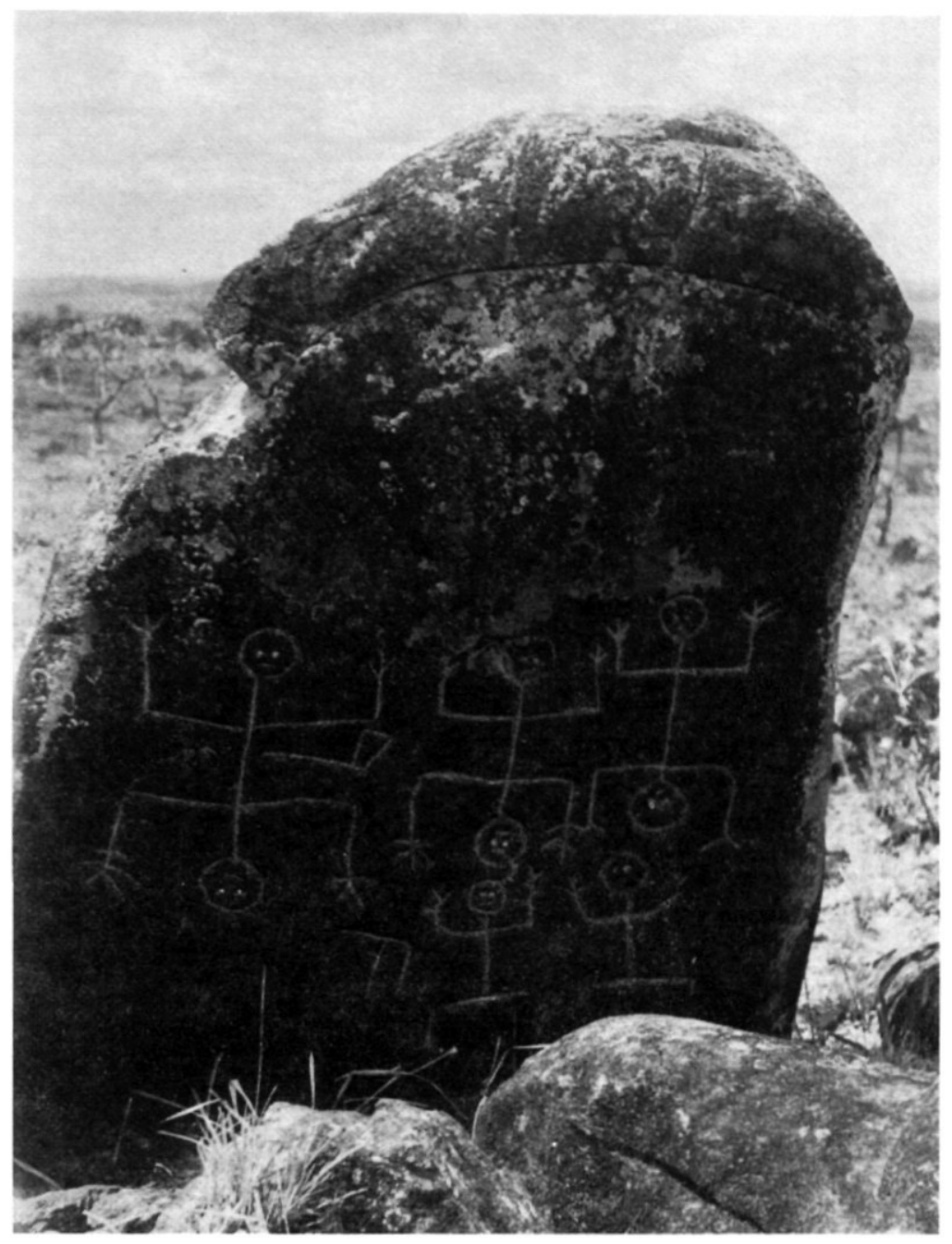

Fig. 4. - De petroglyphen van de Sipaliwinisavanne, met krijt nagetrokken.

Fig. 4. - The Sipaliwini petroglyphs, made clear with chalk. 


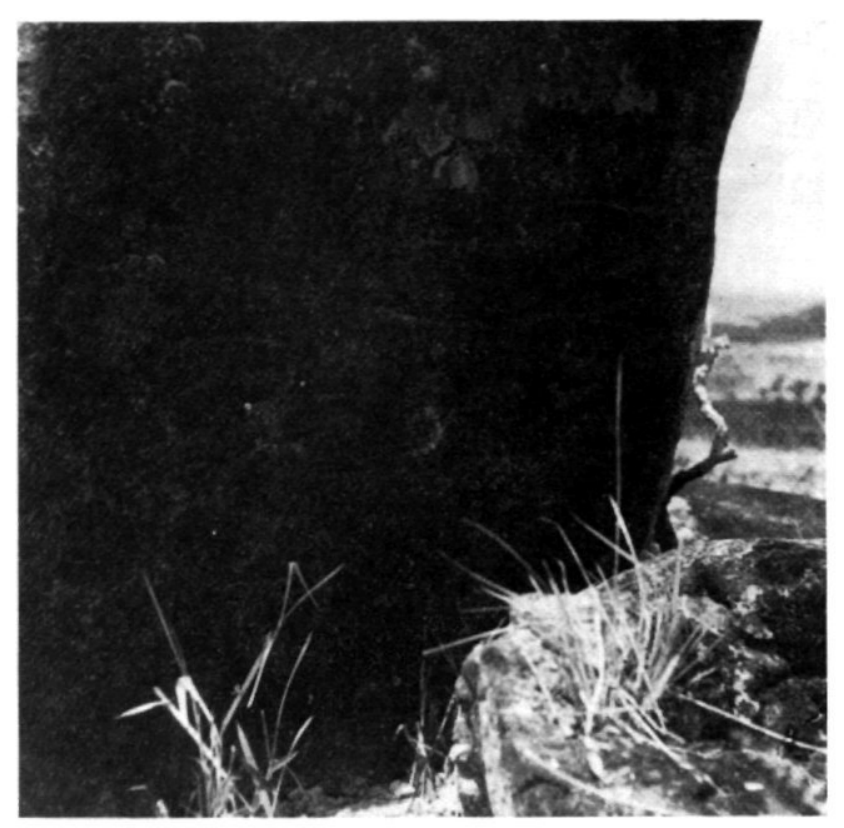

Fig. 5. - De Sipaliwini-figuren zijn nauwelijks zichtbaar. Fig. 5. - The Sipaliwini figures are hardly visible.

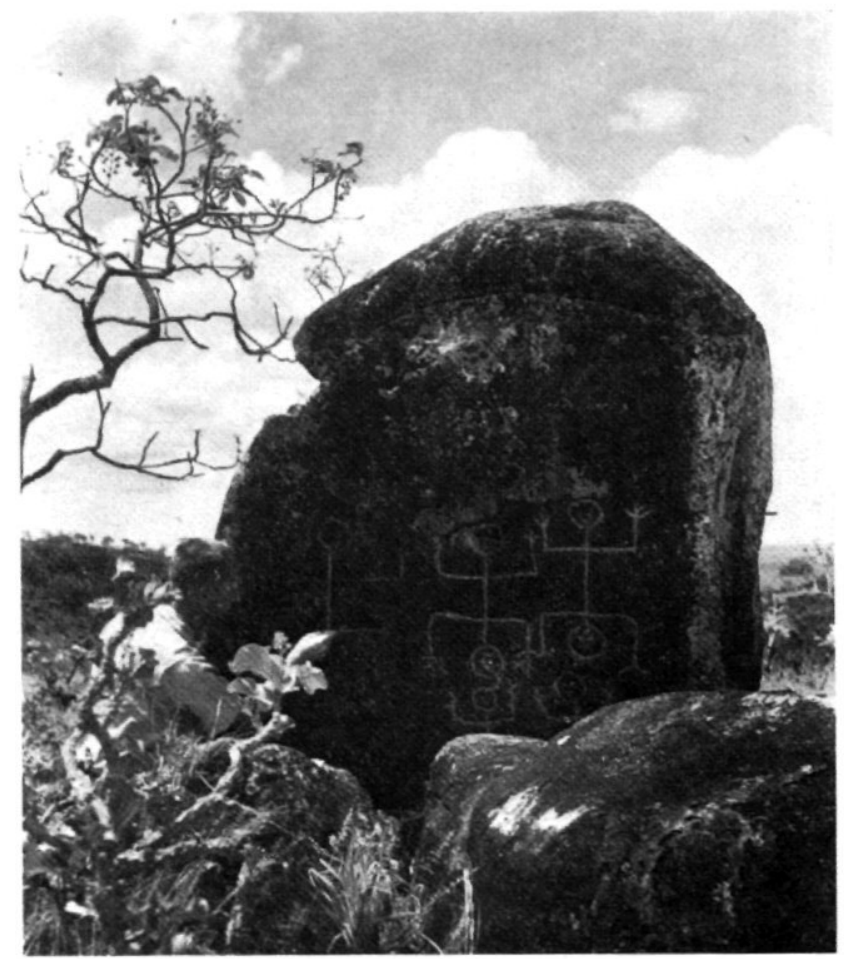

Fig. 6. - De inscripties geven echter een duidelijk beeld nadat zij met krijt zijn nagetrokken. [foto Janssen]

Fig. 6. - The inscriptions are made clearly visible with chalk. 


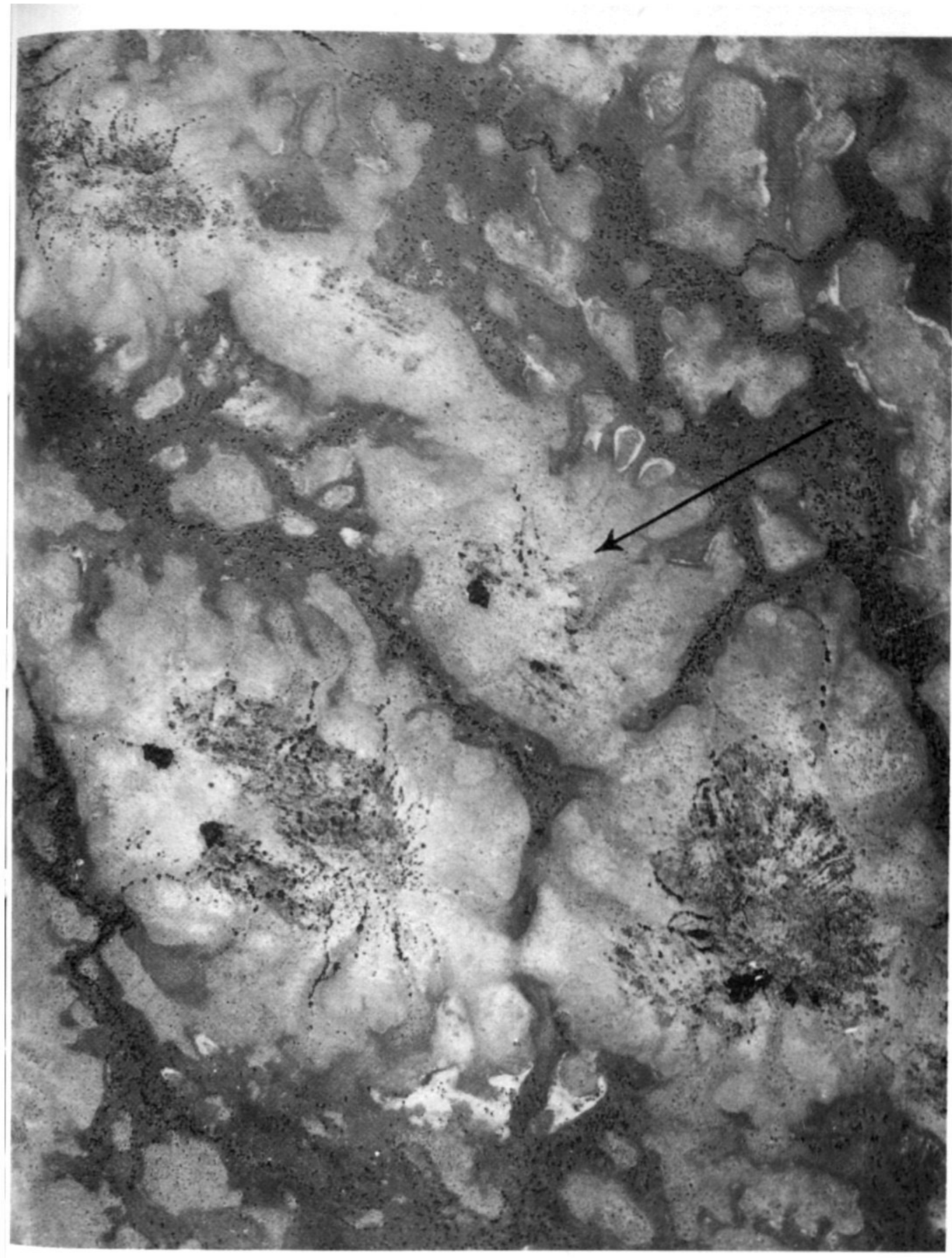

Fig. 7. - Luchtfoto van de Sipaliwinisavanne rondom de inscriptieheuvel (door pijl aangeduid). KLM-Aerocarto, copyright CBL Suriname]. - Licht- en donkergrijs gestreept: grote heuvels, tot (a. $200 \mathrm{~m}$ boven maaiveld, waarvan er drie op Fig. 8 staan aangegeven; verspreide rotsblokken tn open boombegroeiïng. Donkere vlekken: door brand gespaarde bosresten. Egaal lichtgrijze velden : lagere heuvelruggen en plateaux met een open gras- en boombegroeiïng. Egaal donkergrijze relden: laagste terreindelen, nat in regentijd, met dichte kruiden-begroeiïng, Kawfoetoe's; de donkere stipjes zijn Maurisiepalmen (Mauritia flexuosa). Witte vlekken en randen: langs de randen der geulen ingespoelde lagen fijn wit zand, zeer schaars begroeid. - Breedte van het gefotografeerde gebied $2,5 \mathrm{~km}$; noordrichting naar boven.

Fig. 7. - Aerial photograph of a part of the Sipaliwini savanne around the 'inscription hill' (arrow), thowing three hill tops which are indicated in Fig. 8. Light colour: dry grass covered hills and table lands. Dark colour: swamps with Mauritia flexuosa (small dark dots). 


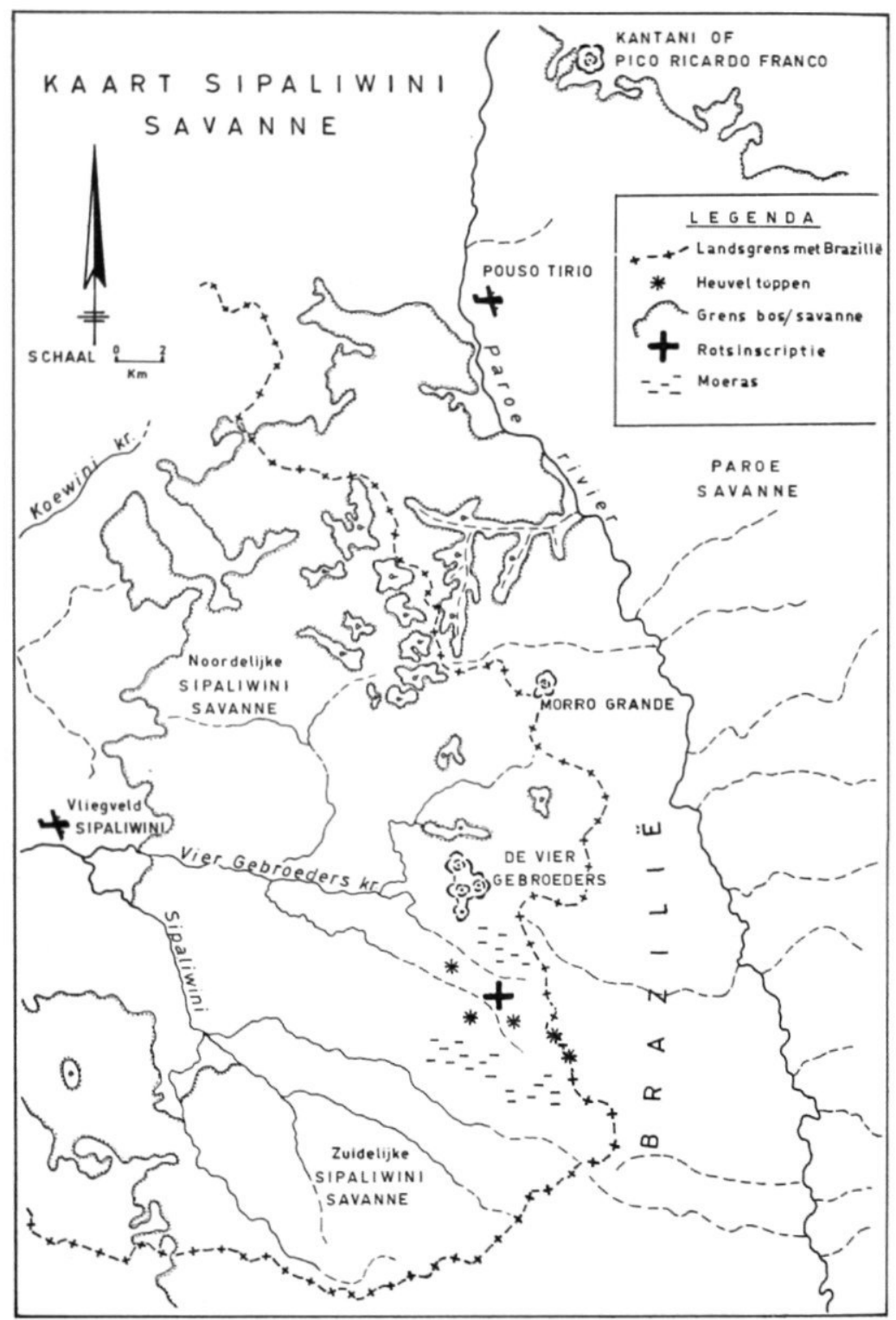

Fig. 8. - Schetskaartje van de Sipaliwinisavanne.

Fig. 8. - Map of the Sipaliwini savanne. Big cross: the inscription; asterisks: hill tops; small stripes: swamps; stippled lines: limits of savanna. 


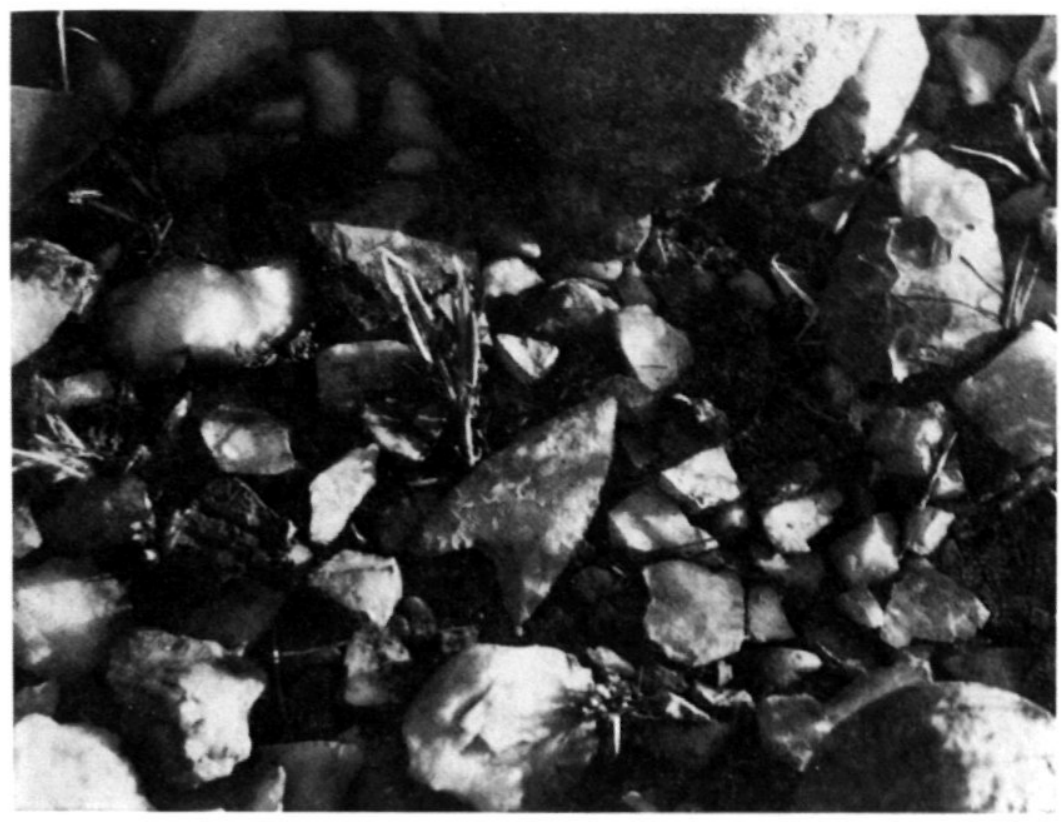

Fig. 9. - Gave pijlspits van kwarts in situ, tussen slagkeien en afval op een voorhistorische werkplaats. Grootste lengte $6 \mathrm{~cm}$, grootste breedte $3,2 \mathrm{~cm}$.

Fig. 9. - Relics of a palaeo-indian workshop in the Sipaliwini savanna.

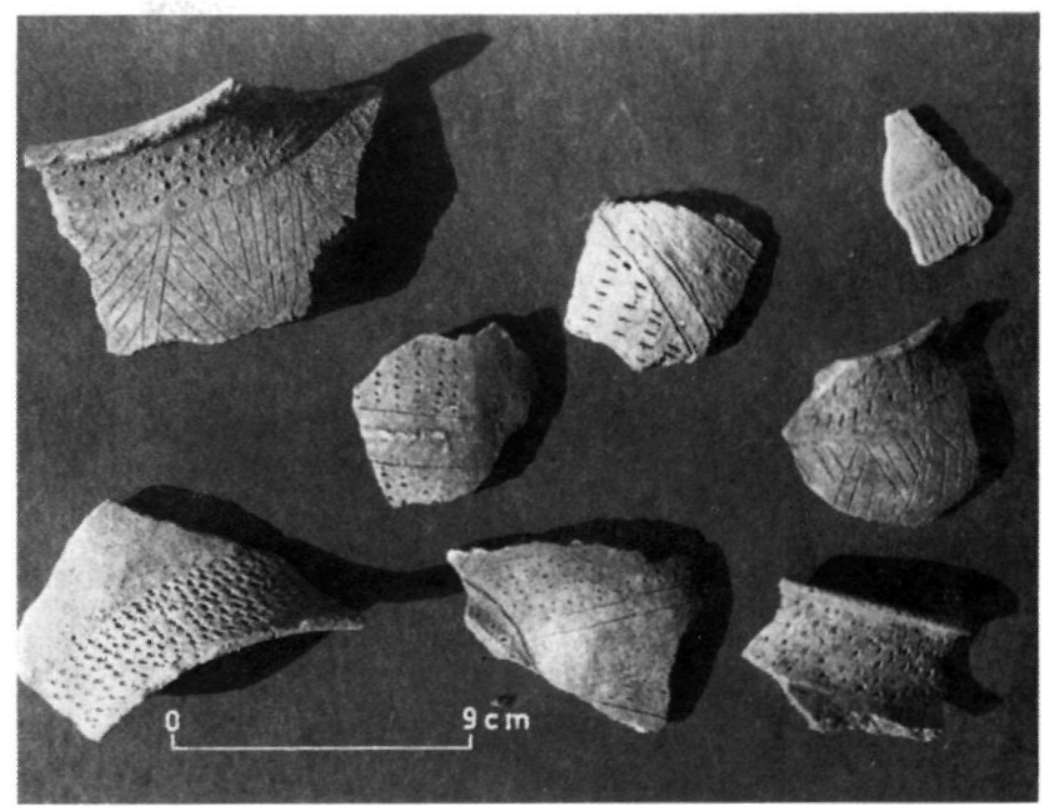

Fig. 1o. - Stukken Taruma-aardewerk van de Morro Grande, Sipaliwini savanne.

Fig. 1o. - Taruma pottery from the Sipaliwini at Morro Grande. 


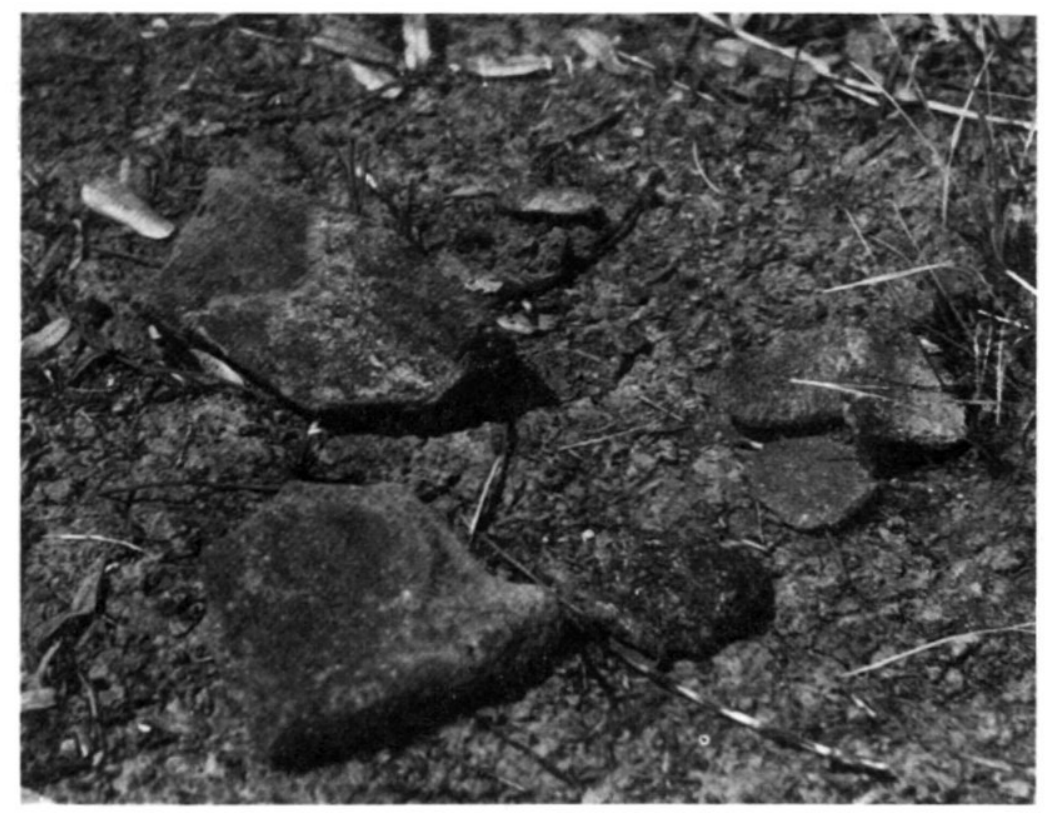

Fig. I I - Grove onversierde potscherven in situ, ten zuiden van de Viergebroederskreek in de Sipaliwinisavanne.

Fig. II. - Pieces of coarse pottery, south of the Viergebroederskreek.

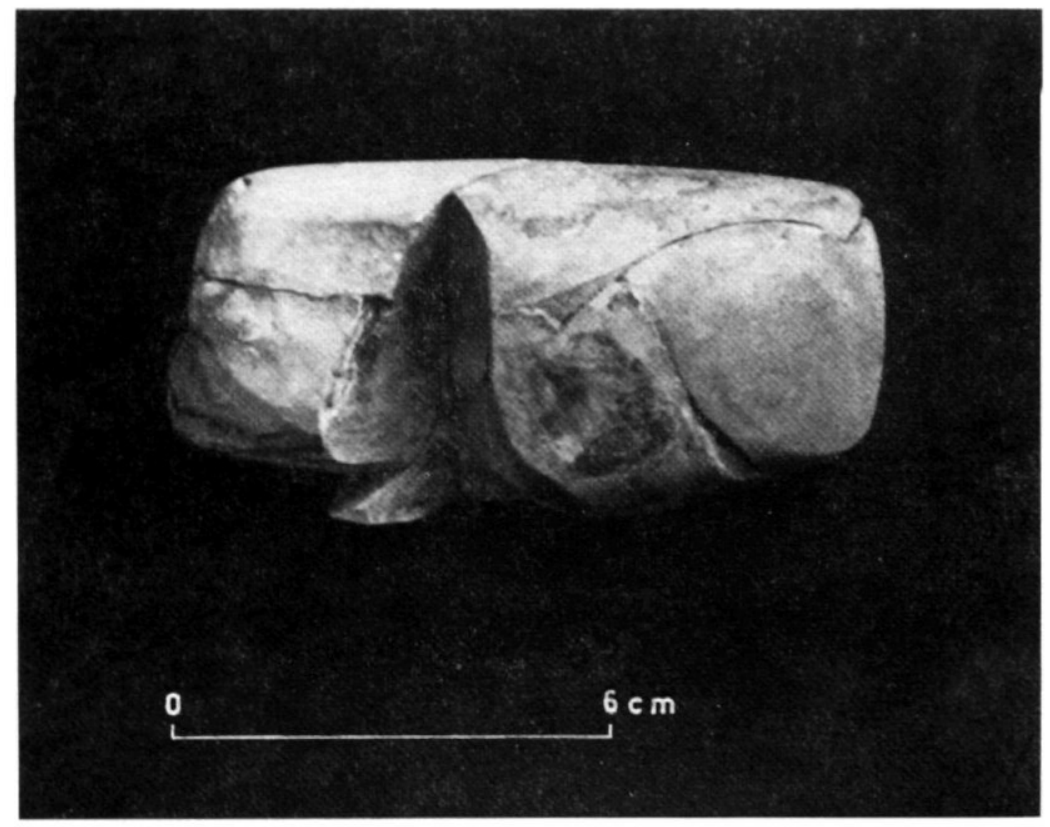

Fig. I2. - Stenen bijl, samengevoegd uit verspreide losse stukken, gevonden op de oostelijke voet van de inscriptieheuvel.

Fig. I2. - Stone ax, reconstructed from scattered pieces found in the Sipaliwini savanna. 


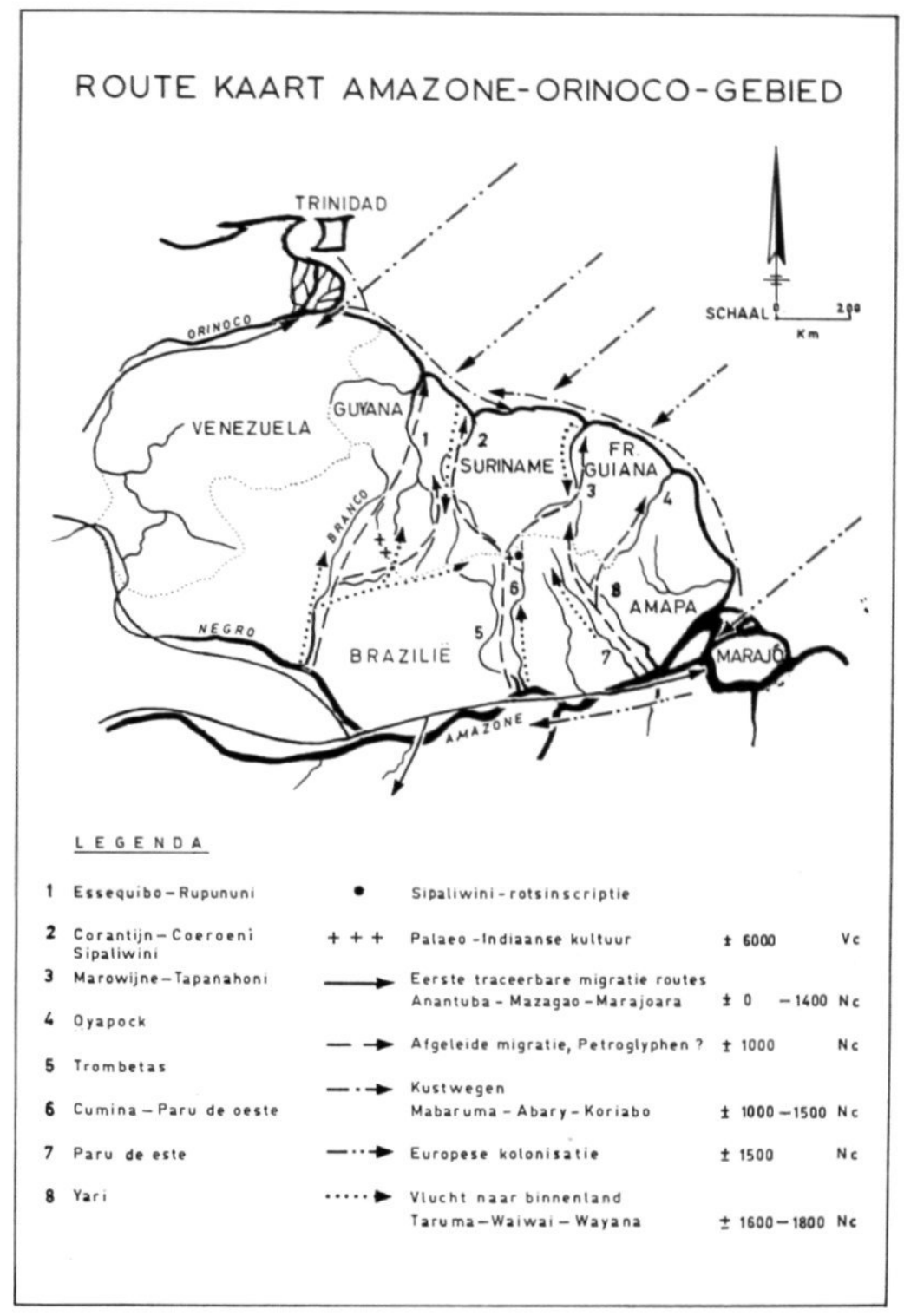

Fig. 13. - Migratie-kaart van Indianenstammen in het Amazone-Orinocogebied. [Vrij naar Evans \& Meggers (I960) en Zerries (I968)].

Fig. 13. - Migration routes in the Amazon and Orinoco river basins. Crosses: palaeo-indian cultures, \pm 6000 B.C.; closed lline: first migration routes, \pm o-I 400 A.D.; dashed line: supposed migration routes, petroglyphs? \pm Iooo A.D.; dash-dot line: coastal routes \pm I000-I500 A.D.; dash-double dot line: European colonization \pm I500 A.D.; dotted line: escape routes to the interior $\pm 1600-1800$ A.D. 


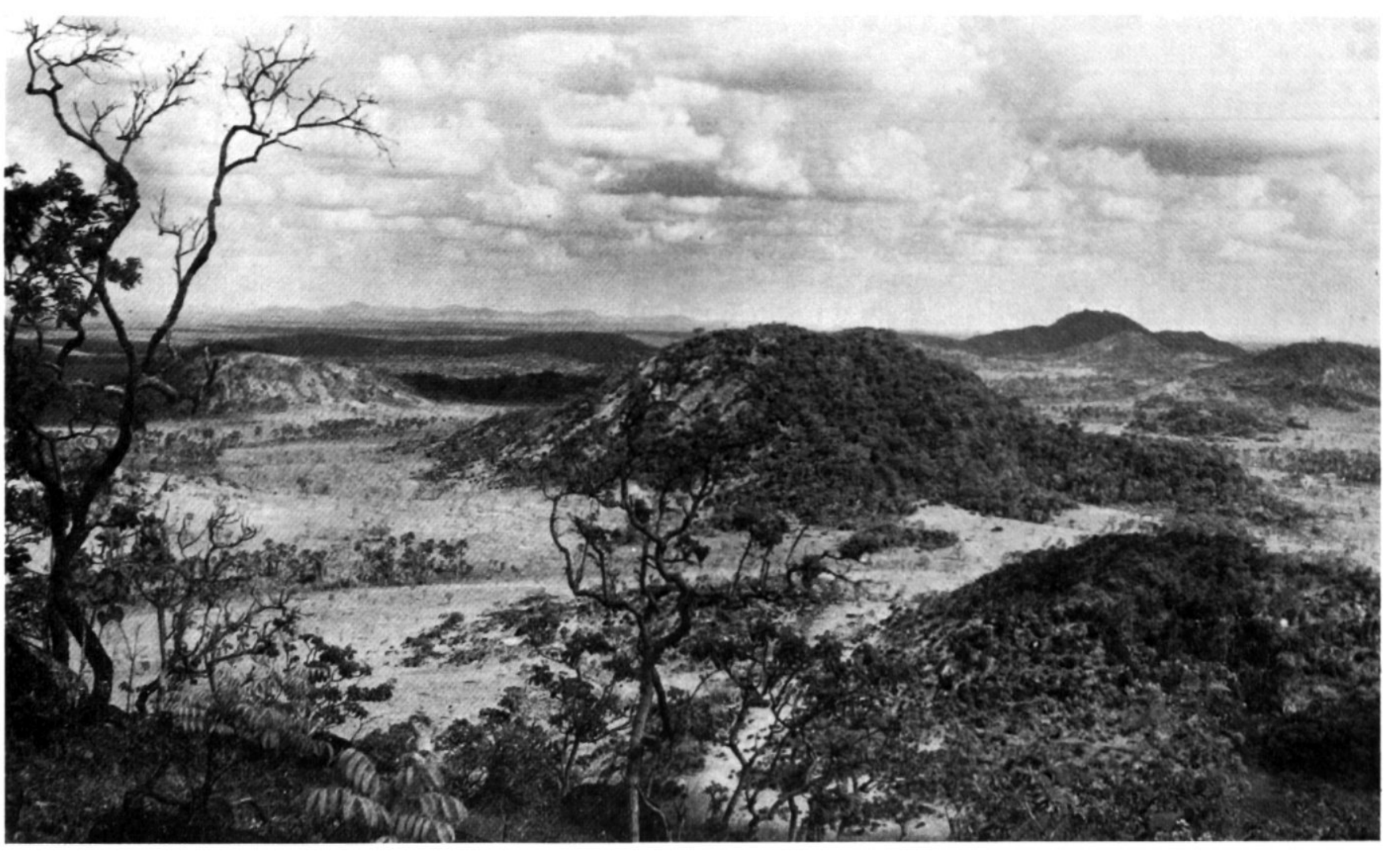

Fig. I4. - Het landschap van de Sipaliwinisavanne is door de afwisseling van open en begroeide terreinen, door de onverwachte vergezichten die zich verliezen in scherp getekende bergketens aan de horizon, en door de allesbeheersende archaïsche sfeer, versterkt door grillig gevormde rotspartijen, van een onvergelijkelijke schoonheid.

liwini savanna landscape with its partly grass- and forest-covered hills and plains, its unexpected panorama's, and its overwhelming prehistoric touch, strongly impresses the visitor. 


\section{NOTEN}

I Im ThURN (I883, p. 39I, 394 en 397) schrijft: "Rock sculptures may ... be distinguished into two kinds, differing in the depth of incision, the apparent mode of execution and, most important of all, the character of the figures represented." - "These two kinds of engravings may, for the sake of convenience be distinguished as deep and shallow respectively, according as the figures are deeply cut into the rock or are merely scratched on the surface. The former vary from one-eighth to one-half of an inch, or even more, in depth; the latter are of quite inconsiderable depth. This difference probably corresponds with a difference in the means by which they were produced. The deep engravings seem cut into the rock with an edged tool, probably of stone; the shallow figures were apparently formed by long continued friction with stones and moist sand." - "The deep engravings ... consist not of a single figure, but of a greater or less number of rude drawings. These depict the human form, monkeys, snakes and other animals and also very simple combinations of two or three straight or curved lines in a pattern and occasionally more elaborate combinations. The individual figures are small averaging from twelve to eighteen inches in height but a considerable number are generally represented in a group."

Het is inderdaad zeer de vraag of het verschil in diepte der groeven alléén fundamenteel kan worden geacht, daar het vaststaat dat eenmaal gemaakte figuren door latere passanten tot in een recent verleden werden nagetrokken en verdiept (КOCH-GRÜNBERG, 1907, en GoNGGRYP, 1920). Het in beschouwing nemen van de groefdiepte in combinatie met de figuurelementen lijkt voorlopig eventueel een goed uitgangspunt voor een indeling.

In KOCH-GrüNBERG (I907, p. 77) lezen wij: "Mehr noch, als die Anhäufung der Felsbilder an manchen Orten, hat die Tiefe der Rillen den Forschern Kopfzerbrechen verursacht, und keiner ist auf eine sehr naheliegende und einfache Erklärung gekommen. Der eine spricht von ungewöhnlicher Ausdauer, die dazu gehört, monatelang eine harte Felsplatte mit unvollkommenen Feuerstein-meisseln zu bearbeiten, der andere weiss es sich nicht zu erklären mit welchen Werkzeugen diese Leute gearbeitet hätten, um so tiefe und dauerhafte Einschnitte hervorzubringen. Als Robert Schomburgk von den Indianern am unteren Rio Negro hörte, die Felsbilder seien durch anhaltende Friktion mit Quarzkieseln eingegraben, machte er sofort einen Versuch der natürlich fruchtlos blieb. Unermüdliche Geduld mag auch hier mit Erfolg gekrönt worden sein, meint der Reisende. Indessen spielt die Geduld, die der Indianer in der Tat in überreichem Masse besitzt, hierbei gar keine Rolle; denn diese tiefen Rillen sind wiederum nicht der fortgesetzten fleissigen Arbeit eines einzelnen zu zu schreiben, sondern der gleichen Betätigung einer Reihe von Menschen, vielleicht ganzer Generationen."

Wanneer we mogen aannemen, dat ten tijde der ontdekkingsreizen vanaf het midden der vorige eeuw de toen levende indianen geen enkele notie hadden van de oorsprong der in hun gebied voorkomende 
petroglyphen ${ }^{5}$ ), dan betekent dat, gezien het bovenstaande, dat de diep ingeslepen petroglyphen ook behoorlijk oud moeten zijn, althans lang onderhouden. Theoretisch kunnen de shallow engravings natuurlijk net zo oud zijn, maar de wetten der oppervlakte verwering van het gesteente, als gevolg van de inwerking van het klimaat, pleiten daartegen. $\mathrm{Er}$ zijn dus zeker gegronde redenen aan te nemen, dat de shallow engravings jonger zijn.

2 Het woord Sipaliwini verraadt een Arowaks-indiaanse afkomst. Volgens DE GOEJE (1909) kan het geen samentrekking zijn tussen de woorden sipali (Karaïbs-indiaans voor rog) en wini (Arowaks voor water, rivier), omdat een dergelijke tweetalige herkomst niet waarschijnlijk is. Volgens ZoNNEvELD (1967) is hier mogelijk sprake van een samentrekking van de Arowakse woorden sipa of siba (steen, rots) en wini.

Het woord savanne of savannah (Spaans: sabána) kreeg het eerst bekendheid door een beschrijving van Oviedo in 1535 van boomloze vlakten op Haïti en Cuba, waarbij het woord van de daar levende Karaïben schijnt te zijn overgenomen. EDEN gebruikt in I555 het woord zauana (LANJouw, I936). In dit verband is het interessant te wijzen op de uitdrukking voor savanne in de in het zuiden der Guyana's gesproken Oayana- en Macusitaal (beide tot de Karaïbse taalfamilie behorend), respectievelijk ona en ouana (DE GOEJE, I906), waarin dezelfde klankkern is te herkennen.

3 ZeRries (I968, p. 376) merkt hierover op: "The cosmos-associated dualism of this race [de Bororo] also extends to the layout of the settlement." - "Among the east Timbira and the Caingang, all natural phenomena, plants and animals are divided, like the tribes, into two opposing groups embodying the idea of east-west antithesis (sunmoon, day-night, red-black and so on)."

4 In de door IJzerman (I9II, p. 656) gepubliceerde reisbeschrijving langs de Boven-Corantijn in 720 schrijft mijndirecteur S. H. SANDERS, als notitie bij een kaartje: "hier is een indiaans dorp met nu komende die van de Portugeezen zijn weggelopen en zich alhier neder gezet hebben, om te woonen; tegens de inlandsche indianen, het is een groot verschil."

5 VAN PANhUYS (1926, p. 485) schrijft - naar aanleiding van een bespreking van FARABEE's boek over The Central Arawaks, p. r69: "In de streek, die door de beschreven Arowakken-stammen wordt bewoond, bevinden zich op rotsen tal van ingegrifte teekeningen (petroglyphen). De Indianen die zich thans in de streek ophouden weten niets van den oorsprong of de beteekenis van deze inschriften en hebben geen tradities of geloof dat op de teekeningen betrekking heeft. Dr. F. houdt ze voor zeer oud en noemt ze de eenige getuigenis van een sedert lang uitgestorven beschaving."

AlEXANDER vON HuMBoldt gaf als zijn mening, in zijn voorwoord tot Schomburgk's Reisen in Guiana und am Orinoko (1841, p. 38): "Ungeachtet der weiten Ausdehnung welche die Einfälle der Ka- 
raïbenstämme erlangten und der alten Macht dieses schönen Menschenschlages kan ich doch nicht glauben, dass dieser ganze ungeheure Gürtel von eingehauenen Felsen, der einen grossen Teil Südamerika's von Westen nach Osten durchschneidet, das Werk der Karaïben sein solle. Es sind vielmehr Spuren einer alten Civilisation die vielleicht einer Epoche angehört, wo die Racen, welche wir heutzutage unterscheiden, nach Namen und Verwandtschaft noch unbekannt waren. Selbst die Ehrfurcht, welche man überall gegen diese rohen Sculpturen der Altvordern hegt, beweist, dass die heutigen Indianer kein Begriff von der Ausführung solcher Werke haben."

6 Meggers \& Evans I963, p. I 44 : “One conclusion is so overwhelmingly documented that future research can only add to its support, namely, that a tremendous amount of contact existed aboriginally between widely separated geographical areas, not only by diffusion from group to group, but in the form of long-range commerce and migration by land and sea."

7 Meggers \& Evans I963, p. I23: "In summary, it can be said that the Amazon Basin was repeatedly invaded in aboriginal times from the west and north by groups bringing different and at least on one occasion more advanced cultural traits. Although pottery characteristics are most easily recognized, many other elements were undoubtedly introduced temporarily or permanently, in restricted regions or broadly diffused throughout the area. What can be reconstructed of their history seems to show that the Tropical Forest pattern was the most effective adaptation to the environment, with the result that features too advanced or otherwise uncongenial to this way of life were slowly but surely lost with the passage of time."

\section{SUMMARY}

As in Guyana, petroglyphs in Surinam are generally called Timehri after the Carib-indian words ti-me-re (painted).

The first Amerindian petroglyphs in Surinam were found about the middle of the last century by SchombURGK (I84I) along the Corantijn river and by KAPPLER (I887) along the Marowijne river. During the following years more petroglyphs were discovered, mainly in the Corantijn basin. Up to now petroglyphs in Surinam have been found exclusively in both border rivers, the Marowijne and the Corantijn. Following IM THURN who distinguished deep engravings and shallow engravings, it can be said that examples of the first group, probably the oldest, are found along in both rivers. Hence it is supposed that the makers of these engravings migrated from south to north, i.e. from the origin of these rivers to the coast. In case of a migration in the opposite direction, the absence of rock carvings in other river systems is hardly conceivable.

The assumption that petroglyphs should occur in the actual border area between Surinam and Brazil, where both the Surinam border rivers originate, is quite obvious. Especially the Sipaliwini - savanna where in I962 palaeo-indian artifacts had been discovered, seemed very promising 
in this respect. Information on rockcarvings near cave entrances in the surrounding Brazilian mountains received in 1968 from Mr. G. P. FRICKEL, founder of a Brazilian mission station among the Trios along the Paru de Oeste river, strongly confirmed this theory.

Finally in 1969 on top of a low hill an isolated slab was found with an Amerindian rockcarving on its eastern side. This carving is the first one discovered in Surinam on dry ground.

The rock carving is situated on the Surinam-side of the watershed between a branch-creek of the Sipaliwini, a tributary of the Corantijn, and a branch-creek of the Brazilian Paru de Oeste, a tributary of the Cumina, which is a tributary of the Trombetas and finally of the Amazon.

The 'inscription hill' is at the northern end of a S.E.-N.W. directed range of hills and small mountains, enclosed on both sides by more or less extensive swamps. The exact location of the hill is on Surinam territory at $\mathrm{I}^{0} 7^{\prime} 36^{\prime \prime} \mathrm{N}$ and $55^{\circ} 6^{\prime} 45^{\prime \prime} \mathrm{W}$.

The slab is approximately $2.2 \mathrm{~m}$ high, $1.2 \mathrm{~m}$ wide and $0.8 \mathrm{~m}$ thick. It has one convex and one flat side; the latter - which is the side of the carving - is directed towards the east. The rock carving is a composition of seven separate figures, five of which are clearly recognizable as human beings. Striking features are: the two headed figures and the systematic difference in dimensions between the left human figure and the other two pairs. The left one is the largest and has a length from head to head of $53 \mathrm{~cm}$ and a width from elbow to elbow of $4 \mathrm{I} \mathrm{cm}$. The two human figures to the right are somewhat smaller and have a length of respectively $46 \mathrm{~cm}$ and $48 \mathrm{~cm}$ and a width of $29 \mathrm{~cm}$ and $28 \mathrm{~cm}$. The two single headed figures are the smallest and have a length of respectively $24 \mathrm{~cm}$ and $25 \mathrm{~cm}$ and a width of $18 \mathrm{~cm}$. The grooves varying in depth to $\max . \mathrm{r} / 2 \mathrm{~cm}$ are clearly visible even on photographs.

Technically and physically these pictures certainly belong to IM THURN's deep engravings. Possibly the two-headed figures may be explained from the general tendency of some Amerindian tribes in Amazonia to divide their world into two opposing entities 3 ).

In the vicinity of the slab a few artifacts were found. As a matter of fact during their many centuries of existence the grass-covered savannas have been subjected to erosion, which resulted in exposure of buried objects and total disturbance of the stratification. To obtain a picture of history one can only try to catalogue the superficial relics.

An inventory of objects on top of the hill produced the following facts: I. A few tiny pieces of flint (obsidian) were found giving evidence of a palaeo-indian hunting culture several thousands of years ago.

2. A few scattered pieces of ornamented pottery, belonging to the historically known neo-indian Taruma culture, indicate that this area was visited again around and/or after the year I 70o A.D.

A search on the eastern hillfoot and on some flat table lands on the other side of a nearby creek resulted in:

3. The find of small concentrations of pieces of rough aged pottery, together with the scattered pieces of a disintegrated stone ax. This type of pottery, sometimes together with pieces of griddles, has been found in several places throughout the entire savanna, mainly along creeks. 
ROTSTEKENINGEN IN DE SIPALIWINISAVANNE I4I

In contrast with the more common river petroglyphs it seems possible to relate the Sipaliwini petroglyphs to the surrounding artifacts. Taking into account type and distribution of these artifacts, an age of about I000 years for the petroglyphs seems most probable. Assuming that a culture later than the palaeo-indian hunting culture is responsible for the petroglyphs, it is highly probable that the Paru de Oeste River, especially in that 'griddle spreading' era, was used as a migration route to the North, just as in later times e.g. by the Tarumas. In this view the assumption that the Sipaliwini inscription must have been made between 2500 and 250 years ago, seems plausible.

\section{LITERATUUR}

AhlBrinck, W., 1926. Vijf maanden in het oerwoud. Rotterdam.

Ahlbrinck, W., I931. Encyclopaedie der Karaiben. Amsterdam.

Dost, H., 1962. Verslag van een bodemverkenning op de Sipaliwinisavanne. Intern Rapport Dienst Bodemkartering, Paramaribo.

Evans, C. \& Meggers, B. J., 1960. Archaeological investigations in British Guiana. Bull. Bur. Amer. Ethn. Washington 177 .

FERIZ, H., I957. Suriname, een reisverslag. Amsterdam.

Geijskes, D. C. 1959. Verslag Coeroeni-expeditie. Intern Rapport Surinaams Museum, Paramaribo.

GoeJE, C. H. DE, 1906. Bijdrage tot de ethnographie der Surinaamsche Indianen. Intern. Archiv Ethnogr. Leiden I7, Suppl., p. 96.

GoeJE, C. H. DE, I908. Verslag der Toemoekhoemak-expeditie. Tijdschr. Kon. Ned. Aardr. Gen. 25, p. 943-1 168.

GoeJE, C. H. DE, I909. Aardrijkskundige namen in Guyana en omliggende landen. Tijdschr. Kon. Ned. Aardr. Gen. 26, p. 278-294.

GoNGGRIJP, J. W., I920. Sporen van voorhistorische bewoners van Suriname. W. I. Gids jrg. 2, p. I-16.

Guppy, N., 1958. Wai Wai (through the forests North of Amazon). London.

Im Thurn, E. F., I883. Among the Indians of Guiana. London.

KAPPler, A., I887. Surinam, sein Land, seine Natur, Bevölkerung und seine Kultur-Verhältnisse, Stuttgart.

Kate, H. ten, i9i6.: Oudheden. Suriname. In: Benjamins \& Snelleman, Encyclopaedie van Nederlandsch West-Indië (I9I4-19I7), p. 54I-543.

Käyser, C. C., I9I2. Verslag der Corantijn-expeditie. Tijdschr. Kon. Ned. Aardr. Gen. 29, p. 442-5I4.

KoCH-GrÜNBERG, Th., 1907. Südamerikanische Felszeichnungen. Berlin. 
Lynden, A. J. H. van, 1939. Op zoek naar Suriname's Zuidgrens. Tijdschr. Kon. Ned. Aardr. Gen. 56, p. 793-881.

Meggers, B. J. \& Evans, C., 1957. Archeological investigations at the mouth of the Amazon. Washington.

Meggers, B. J. \& Evans, C., 1963. Aboriginal cultural development in Latin America. Smiths. Misc. Coll. I46, I.

Panhuys, L. C. van, 1926. In: Boekbespreking van Farabee, The Central Arawaks, 1918. W.I.Gids 7, p. 481-490.

Roth, W. E., 1925. A trip to the far Brazilian border. Christmas Tide, Georgetown. - Zie: SNELlEMAN, 1926.

SснміDт, L., 1942. Verslag van drie reizen naar de Bovenlandsche Indianen. Paramaribo.

SсномвURGK, R. H., I841. Reise in Guiana und am Orinoko (während der Jahre 1835-1839). Leipzig.

SNelleman, I. F., 1926. Walter E. Roth. W.I.Gids 8, p. 31 5-335. - Hierin een vertaling van RотH, A trip to the far Brazilian border, p. 324-335.

StAhEL, G., I92I. Een Indiaansche rotsteekening aan de Kabalebo-rivier (Corantijn). W.I.Gids 3, p. 100-102.

IJzerman, J. W., igir. Twee reizen van Paramaribo, een naar de Parima in 1718 en een naar de boven Corantijn in 1720 . Tijdschr. Kon.Ned. Aardr. Gen. 28 , p. $653-658$.

Zerries, O., 1968. The South American Indians and their culture. In: FirtKau e.a., Biogeography and ecology in South America, I, The Hague, p. 329-388.

Zonneveld, J. I. S., I967. Toponymen in Suriname. Economisch Tijdschr. Kon. Ned. Aardr. Gen. I, p. 369-377.

Foto's van de schrijver, indien niet anders vermeld. 